\title{
Effect of oregano essential oil and benzoic acid supplementation to a low-protein diet on meat quality, fatty acid composition, and lipid stability of longissimus thoracis muscle in pigs
}

Chuanshang Cheng ${ }^{1}$, Xiaming Zhang ${ }^{1}$, Mao Xia ${ }^{1}$, Zuhong Liu' ${ }^{1}$, Hongkui Wei ${ }^{1,2}$, Zhao Deng ${ }^{1}$, Chao Wang ${ }^{1}$, Siwen Jiang ${ }^{2}$ and Jian Peng ${ }^{1,2^{*}}$ (iD

\begin{abstract}
Background: Consumers are becoming increasingly interested in food containing appropriately high concentration of intramuscular fat (IMF) and polyunsaturated fatty acids (PUFA). The supplementation of feed with antioxidants decreases degradation of lipids in muscles thereby enhances nutritional and sensory properties of meat. Two experiments were conducted to determine the effects of adding oregano essential oil (OEO) and benzoic acid (BA) to low-protein, amino acid-supplemented diets on meat quality, sensory profile, fatty acid composition, and lipid oxidation of longissimus thoracis (LT) muscle in pigs.

Methods: In Exp. 1, 21 barrows were housed in metabolism cages and randomly allotted to 1 of 3 diets. The three diets were normal protein diet (NPD), medium protein diet (MPD) and low protein diet (LPD) with 1\% and 2\% less than NPD, respectively. In Exp. 2, 36 barrows were randomly divided into three experimental groups, namely, NPD, LPD, and identical LPD supplemented with blends of OEO (250 mg/kg feed) and BA (1000 mg/kg feed) (LPOB) groups.

Results: No significant effects of diets on meat quality were observed in Exp. 1. The $b^{*}{ }_{45 m i n}$, tenderness, and IMF content in LPD muscle were higher than those in NPD and LPOB muscle. The LT muscle in LPD group contained a higher percentage of oleic acid (C18:1n-9) and a lower percentage of linoleic acid (C18:2n-6) than those in NPD group. Dietary LPOB improved oxidative stability, total superoxide dismutase, and glutathione peroxidase but decreased drip loss in LT muscle.
\end{abstract}

Conclusions: These findings suggest that growing-finishing pigs fed with a low-protein, amino acid-supplemented diet show a high content of intramuscular fat in the longissimus thoracis muscle. Dietary LPOB enhances the antioxidative status by improving antioxidative capacity but deteriorates the sensory attributes by decreasing IMF content of meat.

Keywords: Low-protein diet, Oregano essential oil, Benzoic acid, Fatty acid composition, Lipid stability, Pigs

\footnotetext{
* Correspondence: pengjian@mail.hzau.edu.cn

${ }^{1}$ Department of Animal Nutrition and Feed Science, College of Animal

Science and Technology, Huazhong Agricultural University, Wuhan 430070,

People's Republic of China

${ }^{2}$ The Cooperative Innovation Center for Sustainable Pig Production, Wuhan

430070, People's Republic of China
} 


\section{Background}

During the last few decades, the pork market has been subjected to several changes influenced by consumer demands, which have focused the production toward healthier, safer, and tastier meat. The intramuscular fat (IMF) is crucial for meat palatability, such as tenderness and juiciness, and is an important economic trait in pork production [1-3]. Besides the IMF amounts, consumers are becoming increasingly interested in food containing high concentration of polyunsaturated fatty acids (PUFA). PUFA are considered as functional ingredients to prevent cardiovascular disease $[4,5]$. Hence, meat producers require producing and supplying meat that contains appropriately higher IMF and PUFA.

Dietary methods to manipulate the fat quantity and composition of pork have been previously reported, including low-protein or lysine-deficient diets [3, 6, 7]. A reduced protein diet promoted pork with higher IMF percentage which was more monounsaturated and less polyunsaturated even when balanced with essential amino acids [2, 8]. The tissue-specific increase of expression of stearoyl-CoA desaturase could be one reason for higher de novo synthesis of fatty acids in muscle of pigs fed reduced protein diets [9]. However, unsaturated fatty acids are more sensitive to oxidation than saturated fatty acids (SFA) and particularly vulnerable to peroxidative attack [10]. Moreover, the lipid oxidation in muscle is a major deterioration of nutritional and sensory properties of meat and meat products [11].

Synthetic and natural antioxidants have been used to delay the lipid oxidation in pork [12]. Herbal feed additives and organic acid have been suggested as desirable alternatives to benefit growth performance of the pigs by improving the gut health. Oregano essential oil (OEO) contains the natural and volatile aromatic compounds that exert different biological actions, such as antimicrobial, anti-inflammatory, and antioxidative activities [13]. Carvacrol and thymol, the two main phenolic derivatives that constitute about 81.9 and $3.5 \%$ of OEO, are principally responsible for the activities $[13,14]$. In addition, other minor constituents such as $\gamma$-terpinene and $\rho$-cymene, two monoterpene hydrocarbons that constitute about 4.49 and $3.07 \%$ of OEO, respectively, also contribute to the activities $[15,16]$. In our previous studies, we found that OEO can improve growth performance [17], intestinal barrier integrity [18], and antioxidant enzyme activities in the intestinal tissues [19].

Benzoic acid (BA), as a kind of organic acid, was authorized to be used in growing pigs at the dose of $0.5 \%$ to $1.0 \%$ by European Union in 2003 [20]. Certain research has proposed that BA can improve the growth performance [21], intestinal antioxidant capacity [22], and microecological balance [23]. In addition, previous studies have reported that the combination of herbal essential oils with organic acid produced a synergistic effect on antibacterial activity [24, 25]. However, there is little available information on the effects of long-term the combination of OEO and BA supplementation to a low-protein, amino acid-supplemented diet on antioxidant properties and fatty acid composition of pork production.

Therefore, we firstly evaluated the effects on meat quality of reducing the dietary protein concentration by one to three percentage units. Secondly, our objective was to investigate the effects of long-term OEO and BA supplementation to a reduced-protein, amino acid-supplemented diet on physical and chemical parameters, fatty acid composition, lipid stability, and sensory profile of longissimus thoracis (LT) muscle in growing-finishing pigs.

\section{Methods \\ Animals, diets, and sampling Experiment 1}

In total, 21 healthy crossbred barrows (Landrace $\times$ Large White, 50 days old) with initial BW of $16.31 \pm 1.26 \mathrm{~kg}$ were used in a 95-d trial. Pigs were placed in metabolism cages that were equipped with a feeder and a nipple drinker, fully slatted floors, and a screen floor. The pigs were randomly allotted to one of three diets based on BW in a randomized complete block design with seven replicate pigs per diet. The diets based on corn, distillers dried grains with solubles (DDGS), and soybean meal. Each diet supplemented with $150 \mathrm{mg}$ aureomycin per $\mathrm{kg}$ feed as antibiotic growth promoter. A normal protein diet (NPD) with 170 and $156 \mathrm{~g} \mathrm{CP} / \mathrm{kg}$ with one percentage unit below the nutrient requirements of the National Research Council [26] for the growing and finishing period, respectively. A medium CP level diet (MPD) with $10 \mathrm{~g} \mathrm{CP} / \mathrm{kg}$ less than the NPD for the growing and finishing period, and a low level diet (LPD) with $20 \mathrm{~g} \mathrm{CP} / \mathrm{kg}$ less than the NPD for the two phases. All diets were fortified with Lys, Met, Thr and Trp to meet the requirements of growingfinishing pigs [27]. Nutrient contents of the experimental diets were presented in Table 1. All pigs were allowed ad libitum access to feed and water throughout the experiment.

On day 95, five barrows per treatments were slaughtered at a live weight of $98.95 \pm 4.07 \mathrm{~kg}$. Pigs were electrically stunned, exsanguinated, dehaired, and split down the midline according to standard commercial procedures. Then, fresh LT samples anterior to the 13th rib from the left side carcass were collected and used for the physical analysis. 
Table 1 Nutrient analysis of the experimental diets (\%, as-fed basis) ${ }^{a}$

\begin{tabular}{|c|c|c|c|c|c|c|}
\hline & \multicolumn{3}{|c|}{ Growing pigs } & \multicolumn{3}{|c|}{ Finishing pigs } \\
\hline & NP & MP & LP & NP & MP & LP \\
\hline \multicolumn{7}{|c|}{ Calculated analysis nutrients } \\
\hline Net energy (Kcal/kg) & 2475 & 2475 & 2475 & 2475 & 2475 & 2475 \\
\hline \multicolumn{7}{|l|}{ Analysed nutrients } \\
\hline Crude protein & 17.01 & 16.02 & 15.02 & 15.62 & 14.61 & 13.61 \\
\hline Dry matter & 87.20 & 87.37 & 87.40 & 88.14 & 88.25 & 88.43 \\
\hline Total ash & 6.10 & 6.16 & 6.13 & 5.82 & 5.87 & 5.93 \\
\hline Ether extract & 4.10 & 4.07 & 4.08 & 4.13 & 4.12 & 4.12 \\
\hline \multicolumn{7}{|c|}{ Standardized ileal digestible amino acids } \\
\hline Lysine & 0.98 & 0.97 & 0.97 & 0.81 & 0.84 & 0.82 \\
\hline Methionine & 0.28 & 0.27 & 0.28 & 0.22 & 0.22 & 0.21 \\
\hline Threonine & 0.59 & 0.57 & 0.58 & 0.50 & 0.49 & 0.51 \\
\hline Tryptophan & 0.17 & 0.16 & 0.17 & 0.14 & 0.15 & 0.13 \\
\hline \multicolumn{7}{|c|}{ Fatty acids (\% of total fatty acids) } \\
\hline C16:0 & 21.00 & 21.05 & 21.12 & 21.20 & 21.26 & 21.32 \\
\hline C18:0 & 3.85 & 3.79 & 3.78 & 3.68 & 3.56 & 3.45 \\
\hline C18:1n-9 & 19.40 & 19.50 & 19.70 & 19.64 & 19.75 & 19.92 \\
\hline$C 18: 2 n-6$ & 49.90 & 49.60 & 49.42 & 49.50 & 49.42 & 49.36 \\
\hline C18:3n-3 & 1.41 & 1.39 & 1.40 & 1.41 & 1.40 & 1.39 \\
\hline
\end{tabular}

\section{Experiment 2}

A total of 36 barrows (Large White $\times$ Landrace) with an initial body weight (BW) of $29.55 \pm 1.27 \mathrm{~kg}$ were randomly allotted to 1 of 3 treatments with twelve replicates of one pig per replicate. Pigs were penned individually. The pig pens were kept in an environmentally controlled building with a temperature between 15 and $25{ }^{\circ} \mathrm{C}$. All pigs were provided with ad libitum access to feed and water via semi-automatic individual feeders and nipple drinkers. Pigs in group I and group II were fed with the same NPD and LPD in Exp. 1, respectively, and group III received the same LPD supplemented with $250 \mathrm{mg}$ of OEO and $1000 \mathrm{mg}$ BA per $\mathrm{kg}$ of feed to substitute for aureomycin (LPOB). The OEO was provided by Meritech Bioengineering Company (Guangzhou, China). The components of OEO are shown in Additional file 1. The BA was purchased from Novus International (China).

On day 98, six barrows per treatments were slaughtered at a live weight of $106.53 \pm 3.55 \mathrm{~kg}$. Fresh LT samples anterior to the 13th rib from the left side carcass were collected and used for the physical analysis. Meanwhile, the LT muscle was removed from the left side carcass at the last lumbar vertebra and frozen at $-20{ }^{\circ} \mathrm{C}$ for 3 days until chemical composition, oxidative stability, sensory evaluation, and fatty acid composition analyses were carried out.

\section{Physical parameters}

All the physical parameters measurements were performed on 5 samples/group and 6 samples/group in Exp. 1 and Exp. 2, respectively. Marbling were scored using the National Pork Producer Council standards (marbling from 1 = devoid to $10=$ abundant) [28]. Measurements of $\mathrm{pH}$ at $45 \mathrm{~min}$ and $24 \mathrm{~h}$ postmortem were performed on LT muscles using a $\mathrm{pH}$ meter ( $\mathrm{pH}-\mathrm{STAR}$, SFK-Technology, Denmark). Meat color (MC) at $45 \mathrm{~min}$ and $24 \mathrm{~h}$ in Exp. 1 were measured for 3 times per sample on the cut surface using the OPTO-STAR meat color determinator (Matthäus). Color measurements ( $\mathrm{L}^{*}, \mathrm{a}^{*}$, $\left.\mathrm{b}^{*}\right)$ in Exp. 2 were performed at $45 \mathrm{~min}$ postmortem from a mean of four random readings made with a chromameter (CR-300, Minolta Camera, Osaka, Japan), previously calibrated against a white tile according to the manufacturer's manual. Drip loss and Cooking loss were determined by the method described by Honikel [29]. For drip loss determination, fresh meat samples (approximate $40 \mathrm{~g}$ ) were held in a plastic box on a grid parallel to the fibre direction. The weight loss percentages after 1 (Exp. 1), 2, 4, and 8 days of storage at $4{ }^{\circ} \mathrm{C}$ were calculated. For cooking loss determination, a fresh slice from each sample was weighed (approximate $145 \mathrm{~g}$ ), placed in a plastic bag, and cooked to an internal temperature of $70{ }^{\circ} \mathrm{C}$ in a $75{ }^{\circ} \mathrm{C}$ water bath. The internal temperature was monitored during cooking with a handheld temperature probe. The cooked samples were cooled for $30 \mathrm{~min}$, blotted dry, and weighed. Cooking loss was expressed as the weight change percentage at the end of cooking. Warner-Bratzler shear force (WBSF) was determined in samples cooled at $4{ }^{\circ} \mathrm{C}$ for $24 \mathrm{~h}$. Six cylindrical cores $(10 \mathrm{~mm} \times 10 \mathrm{~mm})$ were removed from each sample parallel to the fiber direction, then, were sheared with a WBSF device attached to an Instron Universal Testing Machine (model 1011, Instron instrument, USA) with a 50-kg tension using a crosshead speed of $100 \mathrm{~mm} / \mathrm{min}$. The peak force (Newton/ $\mathrm{cm}^{2}$ ) was recorded.

\section{Chemical parameters}

Six samples/group of LT muscle were analyzed for dry matter, ash, and crude protein according to the methods of the AOAC [30]. Muscle IMF content was determined by Folch et al. [31]. The content of IMF was expressed as the weight percentage of wet muscle tissue. Each sample was analyzed in triplicate.

\section{Analyses of the fatty acid profile of IMF}

Lipids from LT muscle samples were extracted in chloroform-methanol according to Folch et al. [31]. Fatty acid methyl esters were separated and determined with a CP-3800 Gas Chromatograph [32]. The fatty acids were identified by comparing the retention times 
of the peaks with those of known standards (Sigam Chemical Co., St. Louis, MO, USA). The response factors for the fatty acids were calculated using the same standard mixtures plus an internal standard [32]. Peaks were identified using standards where available (Sigma Chemical Co. Ltd., Poole).

\section{Measurement of antioxidant enzyme activity and oxidative stability}

Approximately $800 \mathrm{mg}$ of frozen muscle sample was weighed and homogenized on ice in $8 \mathrm{ml}$ of $0.9 \%$ saline and then centrifuged at $2300 \times \mathrm{g}$ for $10 \mathrm{~min}$ at $4{ }^{\circ} \mathrm{C}$. The supernatant, which contained soluble enzymes and mitochondrial material, was used to measure enzyme activity and thiobarbituric acid reactive substances (TBARS) level in triplicate at appropriate dilutions. The activities of total superoxide dismutase (T-SOD), catalase (CAT), glutathione peroxidase (GPx), and total antioxidative capacity (T-AOC) in muscle were assayed using colorimetric methods with a spectrophotometer (Biomate 5, Thermo Electron Corporation, Rochester, NY, USA). The assays were conducted with commercial kits purchased from Nanjing Jiancheng Bioengineering Institute (Nanjing, Jiangsu, China) according to the manufacturer's instructions. The total protein content of the supernatant was also determined by a commercial kit from Nanjing Jiancheng Bioengineering Institute (Nanjing, Jiangsu, China).

Oxidative stability of the LT samples were assessed by TBARS method at 1,4 , and 8 days of storage in a refrigerator at $4{ }^{\circ} \mathrm{C}$. The analyses of TBARS were also conducted using commercial kits purchased from Nanjing Jiancheng Bioengineering Institute (Nanjing, Jiangsu, China) according to the manufacturer's instructions. Determinations were carried out in triplicate. The content of TBARS, as an index of MDA, was expressed as nanomoles per milligram protein of muscle tissue.

\section{Acceptance test-eating quality}

Eating quality characteristics were assessed in an acceptance test session according to AMSA [33]. Thirty persons, with previous experience, were recruited from the staff and students of the Department of Animal Science in the Faculty of Animal Nutrition and Feed Regulation. They were typical consumers (25-50 years old) of pork. A practicing session was performed before the test to allow consumers to become familiar with the test procedure, evaluation form, and sample presentation format.

A total of 18 pork samples (6 animals per treatment) were evaluated, and each sample was evaluated five times. Meat pieces $(2.5 \mathrm{~cm}$ thickness $)$ of the three nutritional treatments were cooked, wrapped, cut, and kept warm prior to serving for acceptance test evaluation applying the method of Simitzis et al. [34]. Three attributes (flavor, juiciness, and tenderness) were evaluated with a ten-point descriptive linear continuous scale (1-10) with larger scores indicating a more favorable rating. Overall acceptance was rated on a nine-point hedonic scale (1-9) ranging from dislike extremely to like extremely. Each sample assessment involved three samples that represented the nutritional treatments (NPD, LPD, and LPOB). The paneling room was kept free of nonsample odors, artificial lighting was used, and the temperature was kept constant (approximately $20^{\circ} \mathrm{C}$ ).

\section{Statistical analysis}

Each pig was considered as the experimental unit. The data were analyzed using the Statistical Analysis System (version 8.1; SAS Institute, Cary, NC, USA). Data for physical and chemical parameters, antioxidant enzyme activities, and fatty acid profile of IMF were analyzed by one-way ANOVA where the diet was the main effect. The data on drip loss and TBARS parameters during storage time in Exp. 2 were assessed by a two-way Analysis of Variance (ANOVA) with dietary treatment, time, and their interaction as effects. The attributes of eating quality (flavor, juiciness, tenderness, and overall acceptance) were analyzed using an ANOVA procedure, which contained the fixed effect of nutritional treatment and the effect of animal nested within nutritional treatment as a random effect, with the intention to correct the animal individual differences within treatment. The means were calculated using the least square method and presented with the standard error of the mean (SEM). When a significant $p$-value $(P<0.05$ or $P<0.10)$ was observed in ANOVA, means of dietary treatments were compared using Duncan's multiple comparison, whereas $P<0.10$ was considered a tendency.

\section{Results \\ Physical parameters \\ Exp 1}

The meat quality characteristics of pigs are described in Table 2. There was no signifcant effect of treatment on

Table 2 Effects of reduced-protein, amino acid-supplemented diets on meat quality of pigs

\begin{tabular}{llllll}
\hline tem $^{\mathrm{a}}$ & NPD & MPD & LPD & SEM $^{\mathrm{b}}$ & $P$-value \\
\hline $\mathrm{pH}, 45 \mathrm{~min}$ & 6.17 & 6.26 & 6.22 & 0.07 & 0.880 \\
$\mathrm{pH}$, 24 h & 5.63 & 5.61 & 5.68 & 0.03 & 0.929 \\
MC (45 min) & 70.90 & 69.94 & 66.30 & 1.09 & 0.198 \\
MC (24 h) & 51.69 & 49.55 & 48.79 & 1.03 & 0.528 \\
Drip loss (24 h), \% & 0.95 & 1.07 & 0.96 & 0.04 & 0.568 \\
Intramuscular fat, \% & 2.20 & 2.31 & 2.46 & 0.17 & 0.566 \\
\hline
\end{tabular}

${ }^{\mathrm{a} M C}$ meat color, NPD normal protein diet, MPD medium protein diet, LPD low protein diet

${ }^{\mathrm{b}}$ Standard error of mean, $n=5$ 
$\mathrm{pH}$ values, meat color values, drip $\operatorname{loss}_{24 \mathrm{~h}}$, and IMF content $(P>0.05)$.

\section{Exp 2}

Compared with the LPD group, the NPD and LPOB group showed a lower $(P<0.05) \mathrm{b}^{*} 45 \mathrm{~min}$. There was a tendency to decrease $(P=0.078)$ marbling score of LT muscle in pigs fed LPOB diet compared to dietary LPD. No effects $(P>0.05)$ of dietary treatments were detected on $\mathrm{pH}$ values, $L^{*} 45 \mathrm{~min}, \mathrm{a}^{*} 45 \mathrm{~min}$, cooking loss, and shear force (Table 3). The changes of drip loss of pork LT muscle in relation to dietary treatment (NPD, LPD, and LPOB) and storage time at $4{ }^{\circ} \mathrm{C}$ are shown in Fig. 1 . Drip loss was significantly affected by storage time $(P<0.01)$ and dietary treatment $(P<0.001)$. No interaction between time and treatment was observed $(P>0.05)$.

\section{Chemical parameters}

Pigs fed with LPD had greater $(P=0.054)$ IMF in LT muscle compared with pigs fed with the NPD or LPOB diet (Table 4). Dietary treatments did not affect muscle moisture, crude protein and ash content $(P>0.05)$.

\section{Sensory profile}

The values for tenderness, juiciness, flavor, and overall acceptance of LT muscle sensory profile are reported in Table 5. A LPD diet significantly improved $(P<0.05)$ tenderness of LT muscle compared with the NPD and LPOB diet. No significant difference in the ratings of juiciness, flavor, and overall acceptance of pork LT was detected among nutritional treatment groups (Table 5).

\section{Fatty acid profile of IMF}

The fatty acid profile of total fat in LT muscle is shown in Table 6. Compared with the NPD group, the LPD group contained a higher $(P<0.05)$ percentage of oleic

Table 3 Effects of dietary treatments on physical parameters of longissimus thoracis muscle in pigs

\begin{tabular}{llllll}
\hline Item $^{\mathrm{a}}$ & NPD & LPD & LPOB & SEM $^{\mathrm{b}}$ & $P$-value \\
\hline $\mathrm{pH}$, 45 min & 6.34 & 6.51 & 6.55 & 0.04 & 0.324 \\
$\mathrm{pH}, 24 \mathrm{~h}$ & 5.66 & 5.73 & 5.78 & 0.03 & 0.248 \\
Marbling score & $2.00^{\mathrm{ab}}$ & $2.20^{\mathrm{a}}$ & $1.67^{\mathrm{b}}$ & 0.10 & 0.078 \\
Color indices, 45 min & & & & & \\
$\quad$ Lightness, L & 39.89 & 37.39 & 37.42 & 0.68 & 0.236 \\
$\quad$ Redness, a & 4.58 & 5.04 & 4.41 & 0.29 & 0.680 \\
$\quad$ Yellowness, b & $10.47^{\mathrm{b}}$ & $11.03^{\mathrm{a}}$ & $10.34^{\mathrm{b}}$ & 0.14 & 0.025 \\
Cooking loss, \% & 25.28 & 24.36 & 23.51 & 0.55 & 0.463 \\
Shear force, N/cm & 44.13 & 45.26 & 46.94 & 1.67 & 0.801 \\
\hline
\end{tabular}

Means within a row with different superscript letters are significantly different $(P<0.05)$ or tendency $(P<0.1)$

${ }^{a} N P D$ normal protein group, $L P D$ low protein, amino acid-supplemented group, LPOB $250 \mathrm{mg} / \mathrm{kg}$ oregano essential oil and $1000 \mathrm{mg} / \mathrm{kg}$ benzoic acid group

${ }^{\mathrm{b}}$ Standard error of mean, $n=6$

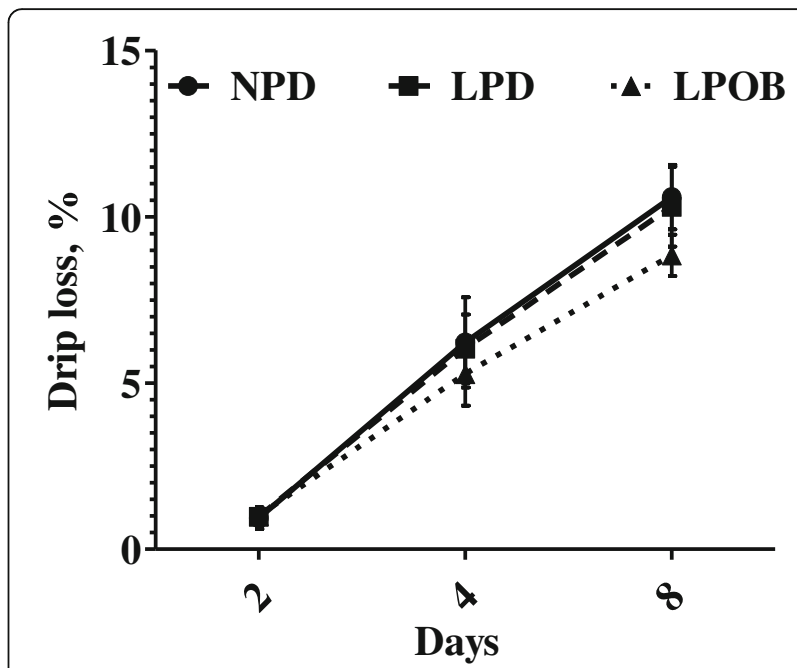

Fig. 1 Longissimus thoracis muscle drip loss in relation to storage time at $4{ }^{\circ} \mathrm{C}$. NPD = normal protein group; LPD = low protein, amino acidsupplemented group; $\mathrm{LPOB}=250 \mathrm{mg} / \mathrm{kg}$ oregano essential oil and $1000 \mathrm{mg} / \mathrm{kg}$ benzoic acid group. Effects of treatment, $P<0.01$; time, $P<0.001$; time $*$ treatment, $P=0.139$

acid (C18:1n-9) and monounsaturated fatty acids (MUFA) and a lower percentage of C18:2n- $6(P<0.05)$ and PUFA $(P=0.089)$. No significant differences $(P>0.05)$ in fatty acid composition was detected between NPD and LPOB.

\section{Oxidative stability and antioxidant enzyme activities}

The dietary inclusion of OEO and BA decreased $(P<0.001)$ lipid peroxidation in LT muscle compared with the NPD and LPD diet. Times of storage also affected oxidative stability in LT muscle $(P<0.001)$ (Fig. 2). No interactions between time and treatment were detected $(P>0.05)$.

Antioxidative enzyme activities in LT muscle are shown in Table 7. Pigs fed with LPOB improved $(P<0.05)$ T-SOD, GSH-Px, and T-AOC activities compared with pigs fed with the NPD and LPD diet. No main effects $(P>0.05)$ were observed in CAT activities of LD muscle among three groups.

Table 4 Effects of dietary treatments on chemical parameters of longissimus thoracis muscle in pigs

\begin{tabular}{llllll}
\hline tem $^{\mathrm{a}}$ & NPD & LPD & LPOB & SEM $^{\mathrm{b}}$ & $P$-value \\
\hline Moisture, \% & 74.33 & 74.53 & 74.90 & 0.10 & 0.114 \\
Crude protein, \% & 22.44 & 22.08 & 22.03 & 0.12 & 0.359 \\
Ash, \% & 2.05 & 1.80 & 1.77 & 0.08 & 0.297 \\
Intramuscular fat, \% & $1.94^{\mathrm{b}}$ & $2.21^{\mathrm{a}}$ & $1.94^{\mathrm{b}}$ & 0.05 & 0.054 \\
\hline
\end{tabular}

Means within a row with different superscript letters are significantly different $(P<0.05)$ or tendency $(P<0.1)$

${ }^{a} N P D$ normal protein group, $L P D$ low protein, amino acid-supplemented group, LPOB $250 \mathrm{mg} / \mathrm{kg}$ oregano essential oil and $1000 \mathrm{mg} / \mathrm{kg}$ benzoic acid group

${ }^{\mathrm{b}} \mathrm{S}$ tandard error of mean, $n=6$ 
Table 5 Effects of dietary treatments on sensory parameters of pork eating quality in pigs

\begin{tabular}{llllll}
\hline Item $^{\mathrm{a}}$ & NPD & LPD & LPOB & SEM $^{\mathrm{b}}$ & $P$-value \\
\hline Tenderness & $3.83^{\mathrm{b}}$ & $4.28^{\mathrm{a}}$ & $3.87^{\mathrm{b}}$ & 0.06 & $<0.01$ \\
Juiciness & 4.84 & 4.97 & 4.89 & 0.06 & 0.646 \\
Flavour & 4.69 & 4.63 & 4.44 & 0.05 & 0.165 \\
Overall acceptance & 5.26 & 5.42 & 5.19 & 0.07 & 0.598 \\
\hline
\end{tabular}

Means within a row with different superscript letters are significantly different $(P<0.05)$

${ }^{a} N P D$ normal protein group, $L P D$ low protein, amino acid-supplemented group, LPOB $250 \mathrm{mg} / \mathrm{kg}$ oregano essential oil and $1000 \mathrm{mg} / \mathrm{kg}$ benzoic acid group

${ }^{b}$ Standard error of mean, $n=6$

\section{Discussion}

Higher IMF content has potential sensory benefits, such as deposition of fat within the muscle could enhance meat quality, i.e., tenderness and flavor [35, 36]. Different feeding strategies have been actively used in meat production to improve IMF [7]. Animal nutrition has a major impact on fat quantity and composition, as seen with low protein or lysine deficient diets that dramatically increase the level of $\operatorname{IMF}[2,3,6]$. In the present

Table 6 Effects of dietary treatments on fatty acid composition (\%) of longissimus thoracis muscle

\begin{tabular}{llllll}
\hline Item $^{\mathrm{a}}$ & NPD & LPD & LPOB & SEM $^{\mathrm{b}}$ & $P$-value \\
\hline C14:0 & 1.16 & 1.01 & 1.33 & 0.07 & 0.141 \\
C16:0 & 23.52 & 23.07 & 24.39 & 0.54 & 0.620 \\
C16:1n-9 & 3.06 & 2.97 & 3.09 & 0.14 & 0.945 \\
C17:0 & 0.19 & 0.20 & 0.22 & 0.01 & 0.494 \\
C18:0 & 11.63 & 12.82 & 12.02 & 0.30 & 0.279 \\
C18:1n-9 & $38.02^{\mathrm{b}}$ & $40.20^{\mathrm{a}}$ & $39.56^{\mathrm{ab}}$ & 0.36 & 0.029 \\
C18:2n-6 & $12.69^{\mathrm{a}}$ & $10.10^{\mathrm{b}}$ & $11.06^{\mathrm{ab}}$ & 0.41 & 0.015 \\
C18:3n-3 & 0.29 & 0.25 & 0.24 & 0.01 & 0.230 \\
C20:0 & 0.15 & 0.15 & 0.16 & $<0.01$ & 0.851 \\
C20:2n-6 & 0.32 & 0.29 & 0.30 & 0.01 & 0.421 \\
C20:3n-3 & 0.27 & 0.30 & 0.29 & 0.01 & 0.630 \\
C20:4n-6 $^{2}$ & 2.30 & 2.39 & 2.48 & 0.14 & 0.875 \\
C22:5n-3 $^{2}$ & 0.51 & 0.53 & 0.50 & 0.04 & 0.951 \\
SFA & 36.65 & 37.25 & 38.12 & 0.46 & 0.452 \\
MUFA & $41.08^{\mathrm{b}}$ & $43.17^{\mathrm{a}}$ & $42.64^{\mathrm{ab}}$ & 0.36 & 0.039 \\
PUFA $^{\mathrm{e}}$ & $16.38^{\mathrm{a}}$ & $13.86^{\mathrm{b}}$ & $14.87^{\mathrm{ab}}$ & 0.48 & 0.089 \\
\hline The & & & &
\end{tabular}

The fatty acid results were presented as $\mathrm{g} / 100 \mathrm{~g}$ fatty acids (wt\%). Means within a row with different superscript letters are significantly different $(P<0.05)$ or tendency $(P<0.1)$

${ }^{\mathrm{a}} N P D$ normal protein group, $L P D$ low protein, amino acid-supplemented group, LPOB $250 \mathrm{mg} / \mathrm{kg}$ oregano essential oil and $1000 \mathrm{mg} / \mathrm{kg}$ benzoic acid group

${ }^{\mathrm{b}}$ Standard error of mean, $n=6$

'Saturated fatty acids (SFA) percentage is the sum of 14:0, 16:0, 17:0, 18:0, and 20:0

${ }^{\mathrm{d}}$ Monounsaturated fatty acids (MUFA) percentage was calculated as the sum of $c 16: 1 n-9$ and $c 18: 1 n-9$

epolyunsaturated fatty acids (PUFA) percentage was calculated as the sum of $18: 2 n-6,18: 3 n-3,20: 2 n-6,20: 3 n-3,20: 4 n-6$, and 22:5n-3

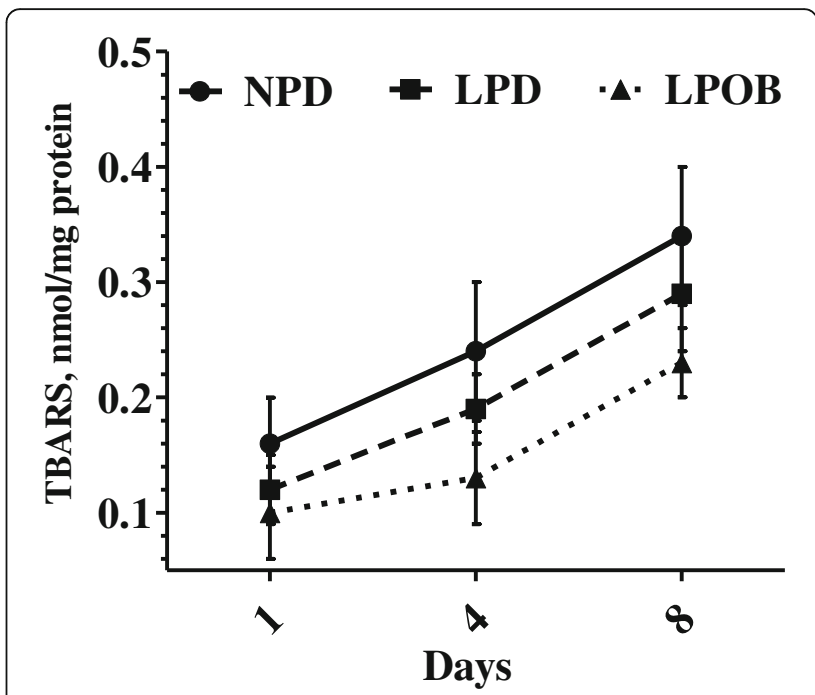

Fig. 2 Oxidative stability during refrigerated storage at $4{ }^{\circ} \mathrm{C}$ of Longissimus thoracis muscle. NPD = normal protein group; LPD = low protein, amino acid-supplemented group; $\mathrm{LPOB}=250 \mathrm{mg} / \mathrm{kg}$ oregano essential oil and $1000 \mathrm{mg} / \mathrm{kg}$ benzoic acid group; TBARS, thiobarbituric acid reactive substances. Effects of treatment, $P<0.001$; time, $P<0.001$; time $*$ treatment, $P=0.309$

study, the results of Exp. 1 indicated that pigs can feed low protein diet reducing dietary protein concentration by one to three percentage units without affecting meat quality of pigs. However, numerically, the values of IMF increased $11.8 \%$ in the LPD group compared with the NPD group, indeed, the results of Exp. 2 demonstrated that the IMF level in LT muscle of pigs was increased by LPD compared with NPD. In some cases, the effect has been explained by the different slaughter age [37] and slaughter weight [38] between the two trials, which were greater in Exp. 2 than in Exp. 1. Normal growth conditions, fat deposition of pigs occurs mainly in the late stages of fattening [39]. Therefore, the effect of dietary treatment on IMF was reflected in Exp. 2. The same result was observed in pigs fed with reduced protein diets balanced with five amino acids from $40 \mathrm{~kg}$ to $115 \mathrm{~kg}$ live

Table 7 Effect of dietary treatments on Longissimus thoracis antioxidative enzyme activities of growing-finishing pigs

\begin{tabular}{llllll}
\hline Item $^{\mathrm{a}}$ & NPD & LPD & LPOB & SEM & $P$-value \\
\hline T-SOD (U/mg prot) & $24.72^{\mathrm{b}}$ & $22.77^{\mathrm{b}}$ & $29.77^{\mathrm{a}}$ & 0.94 & $<0.01$ \\
CAT (U/mg prot) & 0.78 & 0.37 & 0.52 & 0.11 & 0.285 \\
GSH-Px (U/mg prot) & $3.32^{\mathrm{b}}$ & $3.12^{\mathrm{b}}$ & $7.29^{\mathrm{a}}$ & 0.62 & $<0.01$ \\
T-AOC (U/mg prot) & $0.50^{\mathrm{b}}$ & $0.48^{\mathrm{b}}$ & $0.60^{\mathrm{a}}$ & 0.02 & 0.011
\end{tabular}

Means within a row with different superscript letters are significantly different $(P<0.05)$

${ }^{a} N P D$ normal protein group, $L P D$ low protein, amino acid-supplemented group, $\angle P O B 250 \mathrm{mg} / \mathrm{kg}$ oregano essential oil and $1000 \mathrm{mg} / \mathrm{kg}$ benzoic acid group, $T-A O C$ total antioxidative capacity, $T$-SOD total superoxide dismutase, CAT catalase, GPx glutathione peroxidase

${ }^{\mathrm{b}}$ Standard error of mean, $n=6$ 
weight [3]. On the other hand, meat from NPD and NPOB groups with high IMF content exhibited high b* values. Similarly, Alonso et al. [3] reported that low-protein diets increased the yellowness values of LT muscle. Sensory profile results showed that the muscle steaks with the higher IMF content, from regime LPD, had the higher scores for tenderness which agree with the findings of other researchers $[2,3]$ who reported that feeding protein-deficient diets improved the tenderness. There is no previously published research concerning the effects of the administration of a combination of OEO and BA on IMF content in muscles. Noteworthy, blends of OEO and BA substitute for antibiotic in a reduced-crude protein diet can reduce IMF, marbling scores, $\mathrm{b}^{*} 45 \mathrm{~min}$ value and tenderness of LT muscle in the present study. Some studies have suggested that the addition of OEO alone to the diet didn't affect IMF content of animals [34, 40]. Kelly et al. [41] suggested that the average back fat thickness of the males was significantly (5\%) increased as a result of aureomycin supplementation. Cho et al. [42] used mice to demonstrate that subtherapeutic antibiotic treatment promotes adiposity. Therefore, the use of blends of OEO and BA instead of antibiotics may affect lipid metabolism in LT muscle.

In addition to the quantity of lipids, The crude protein restriction during growing-finishing period resulted in an increase of MUFA and oleic acid (C18:1n-9) and in a decrease of linoleic acid (C18:2n-6) in accordance with Wood et al. [3] C18:1n-9 is the main product of de novo fat synthesis in the pig, and its concentration increases as the pig contains more IMF content. Wood et al. [3] also reported that a low-protein, amino acid-supplemented diet increased the percentages of C18:1n-9 and decreased the level of of C18:2n-6. No data regarding fatty acid composition of pork derived from animals fed with a combination of OEO and BA can be found in the literature, and data regarding OEO alone are scarce [43].

Lipid peroxidation is a natural phenomenon that has a significant effect on meat quality [44]. This study is the first to demonstrate that dietary supplementation with a combination of $\mathrm{OEO}$ and $\mathrm{BA}$ in growingfinishing pigs can beneficially increase T-SOD, GPx, and T-AOC activities in muscle which indicate an improved antioxidative capacity. These findings were in accordance with our previous studies reporting the positive effect of OEO on the activities of antioxidant enzymes in vitro and in vivo $[17,19]$. Concerning the possible effects of the BA, the dietary inclusion of $0.5 \%$ BA increased GSH-Px activities in the liver of piglets [45]. High antioxidative enzymes may protect the lipid from oxidative damage [46]. The protection against lipid oxidation in the LPOB group was also confirmed by lower TBARS concentration and drip loss in the
LPOB group during refrigerated storage at $4{ }^{\circ} \mathrm{C}$. The protective effect of OEO, when used as a dietary supplement, on meat lipid oxidation has already been reported [17, 34, 40]. In contrast, Simitzis et al. [34] did not find any effect on stored pig meat when different concentrations of oregano essential oils $(0.25,0.5$ and $1 \mathrm{~mL} / \mathrm{kg}$ feed) were added to the diet. Furthermore, the key to minimizing drip loss was to protect the integrity of cell membranes from freeze injury, which increases their permeability and results in leakage of sarcoplasmic fluid [47]. Dietary supplementation with OEO and BA may preserve the fluidity of the membranes, which could otherwise be adversely affected by oxidative changes in the phospholipids [48]. These results agree with previously published reports, in which to the drip loss appeared to in pigs fed with diets supplemented with OEO [17, 43]. Therefore, results indicated that the LPOB diet improved the antioxidative status in LT muscle, extending the shelf life of meat.

\section{Conclusions}

In this study, growing-finishing pigs fed with a reduced-protein, amino acid-supplemented diet showed a higher content of intramuscular fat in the longissimus thoracis muscle and a changed fatty acid composition towards a higher percentage of oleic acid and a lower percentage of linoleic acid in longissimus thoracis muscle. Low protein diets supplemented with the combination of oregano essential oil and benzoic acid may be an effective means to increase the growing-finishing pigs antioxidant status, to prevent lipid oxidation and, thus, to delay meat shelf-life. However, the long term supplementation blends of oregano essential oil and benzoic acid to low protein diet will reduce the content of intramuscular fat in LT muscle, which have a poor sensory characteristic.

\section{Additional file}

\section{Additional file 1: Chemical composition of oregano essential oil.} (PDF $256 \mathrm{~kb}$ )

\section{Abbreviations}

BA: Benzoic acid; CAT: Catalase; DDGS: Distillers dried grains with solubles; GPx: Glutathione peroxidase; IMF: Intramuscular fat; LPD: Low protein diet; LPOB: Low protein diet supplemented with oregano essential oil and benzoic acid; LT: Longissimus thoracis; MC: Meat color; MPD: Medium level diet; MUFA: Monounsaturated fatty acids; NPD: Normal protein diet; OEO: Oregano essential oil; PUFA: Polyunsaturated fatty acids; SFA: Saturated fatty acids; T-AOC: Total antioxidative capacity; TBARS: Thiobarbituric acid reactive substances; T-SOD: Total superoxide dismutase; WBSF: Warnerbratzler shear force 


\section{Funding}

This study was supported financially by China Agriculture Research System CARS-36 (2017YFD0502004) and the Key Technology Research and Development Program of Hubei Province (No. 2016ABA113).

\section{Availability of data and materials}

All data generated or analysed during this study are included in the supplementary information files of this article.

\section{Authors' contributions}

CC, SJ, and JP designed the study. CC, XZ, MX, HW, ZD, CW, and ZL performed experiments and analyzed the data. CC drafted the manuscript, and SJ and JP reviewed the manuscript. All authors read and approved the final manuscript.

\section{Ethics approval and consent to participate}

Two experiments were approved by the Huazhong Agricultural University Animal Care and Use Committee guidelines, and the treatment, housing, husbandry, and slaughtering conditions conformed to the Experimental Animal Care and Use Guidelines of China.

\section{Consent for publication}

Not applicable.

\section{Competing interests}

The authors declare that they have no competing interests.

\section{Publisher's Note}

Springer Nature remains neutral with regard to jurisdictional claims in published maps and institutional affiliations.

Received: 1 May 2017 Accepted: 11 July 2017

Published online: 31 August 2017

\section{References}

1. Font-i-Furnols M, Tous N, Esteve-Garcia E, Gispert M. Do all the consumers accept marbling in the same way? The relationship between eating and visual acceptability of pork with different intramuscular fat content. Meat Sci. 2012;91:448-53.

2. Teye GA, Sheard PR, Whittington FM, Nute GR, Stewart A, Wood JD Influence of dietary oils and protein level on pork quality. 1. Effects on muscle fatty acid composition, carcass, meat and eating quality. Meat Sci. 2006;73:157-65.

3. Wood JD, Lambe NR, Walling GA, Whitney H, Jagger S, Fullarton PJ, et al. Effects of low protein diets on pigs with a lean genotype. 1. Carcass composition measured by dissection and muscle fatty acid composition. Meat Sci. 2013;95:123-8.

4. Simopoulos AP. N-3 fatty acids and human health: defining strategies for public policy. Lipids. 2001;36:83-9.

5. Fedor D, Kelley DS. Prevention of insulin resistance by $n-3$ polyunsaturated fatty acids. Curr Opin Clin Nutr. 2009;12:138-46.

6. Bidner BS, Ellis M, Witte DP, Carr SN, Mckeith FK. Influence of dietary lysine level, pre-slaughter fasting, and rendement napole genotype on fresh pork quality. Meat Sci. 2004;68:53-60.

7. Alonso V, Campo MDM, Provincial L, Roncalés $P$, Beltrán JA. Effect of protein level in commercial diets on pork meat quality. Meat Sci. 2010;85:7-14.

8. Suárez-Belloch J, Latorre MA, Guada JA. The effect of protein restriction during the growing period on carcass, meat and fat quality of heavy barrows and gilts. Meat Sci. 2016;112:16-23.

9. Doran O, Moule SK, Teye GA, et al. A reduced protein diet induces stearoylCoA desaturase protein expression in pig muscle but not in subcutaneous adipose tissue: relationship with intramuscular lipid formation. Brit J Nutr. 2006;95:609-17.

10. Cortinas L, Barroeta A, Villaverde C, Galobart J, Guardiola F, Baucells MD. Influence of dietary polyunsaturated level on chicken meat quality: lipid oxidation. Poult Sci. 2005;84:48-55.

11. Faustman C, Sun Q, Mancini R, Suman SP. Myoglobin and lipid oxidation interactions: mechanistic bases and control. Meat Sci. 2010;86:86-94

12. Corino C, Oriani G, Pantaleo L, Pastorelli G, Salvatori G. Influence of dietary vitamin e supplementation on "heavy" pig carcass characteristics, meat quality, and vitamin e status. J Anim Sci. 1999;77:1755-61.
13. Bakkali F, Averbeck S, Averbeck D, Idaomar M. Biological effects of essential oils - a review. Food Chem Toxicol. 2008:46:446-75.

14. Yanishlieva NV, Marinova EM, Gordon MH, et al. Antioxidant activity and mechanism of action of thymol and carvacrol in two lipid systems. Food Chem. 1999;64:59-66.

15. de Oliveira TM, de Carvalho RB, da Costa IH, et al. Evaluation of p-cymene, a natural antioxidant. Pharm Biol. 2015;53:423-8.

16. Foti MC, Ingold KU. Mechanism of inhibition of lipid peroxidation by $\mathrm{Y}^{-}$ terpinene, an unusual and potentially useful hydrocarbon antioxidant. J Agr Food Chem. 2003;51:2758-65.

17. Zou Y, Xiang Q, Wang J, Wei H, Peng J. Effects of oregano essential oil or quercetin supplementation on body weight loss, carcass characteristics, meat quality and antioxidant status in finishing pigs under transport stress. Livest Sci. 2016;192:33-8

18. Zou Y, Xiang Q, Wang J, Peng J, Wei H. Oregano essential oil improves intestinal morphology and expression of tight junction proteins associated with modulation of selected intestinal bacteria and immune status in a pig model. Biomed Res Int. 2016;2016:5436738.

19. Zou Y, Wang J, Peng J, Wei H. Oregano essential oil induces SOD1 and GSH expression through Nrf2 activation and alleviates hydrogen peroxideinduced oxidative damage in IPEC-J2 cells. Oxidative Med Cell Longev. 2016;2016:5987183.

20. European Food Safety Authority. Opinion of the scientific panel on additives and products or substances used in animal feed on the safety and efficacy of VevoVitall ${ }^{\circledast}$ (benzoic acid) as feed additive for pigs for fattening. EFSA J. 2007:457:1-14.

21. Kluge H, Broz J, Eder K, Torrallardona D, Brufau J, Estevegarcia E, et al. Effects of dietary benzoic acid on urinary $\mathrm{pH}$ and nutrient digestibility in lactating sows. Livest Sci. 2010;134:119-21.

22. Hui D, Gao Z, Bing Y, Ping Z, He J, Jie Y, et al. Effects of benzoic acid $\left(\right.$ VevoVitall $\left.{ }^{\oplus}\right)$ on the performance and jejunal digestive physiology in young pigs. J Anim Sci and Biotechnol. 2016;7:32.

23. Torrallardona D, Badiola I, Broz J. Effects of benzoic acid on performance and ecology of gastrointestinal microbiota in weanling piglets. Livest Sci. 2007;108:210-3.

24. Giannenas I, Papaneophytou CP, Tsalie E, Pappas I, Triantafillou E, Tontis D, et al. Dietary supplementation of benzoic acid and essential oil compounds affects buffering capacity of the feeds, performance of Turkey Poults and their antioxidant status, $\mathrm{pH}$ in the digestive tract, intestinal microbiota and morphology. Asian Australas J Anim Scis. 2014;27:225-36.

25. Diao H, Zheng P, Yu B, He J, Mao X, Yu J, et al. Effects of benzoic acid and thymol on growth performance and gut characteristics of weaned piglets. Asian Australas J Anim Scis. 2015;28:827-39.

26. National Research Council. Nutrient requirements of swine. 10th rev ed. Washington: National Academy Press; 1998.

27. National Research Council. Nutrient requirements of swine. 11th rev ed. Washington: National Academy Press; 2012

28. NPPC. Official color and marbling standards. Des Moines: Natl Pork Prod Council, IA; 1999.

29. Honikel KO. Reference methods for the assessment of physical characteristics of meat. Meat Sci. 1998;49:447-57.

30. AOAC. Association of Official Analytical Communities. Official methods of analysis of AOAC international. 17 $7^{\text {th }}$ edittion. AOAC: Gaithersburg; 2000.

31. Folch J, Lees M, Sloane-Stanley GH. A simple method for the isolation and purification of total lipids from animal tissues. J Biol Chem. 1957;226:497-509.

32. Luo HF, Wei HK, Huang FR, Zheng Z, Jiang SW, Jian P. The effect of linseed on intramuscular fat content and Adipogenesis related genes in skeletal muscle of pigs. Lipids. 2009;44:999-1010.

33. AMSA. Research guidelines for cookery, sensory evaluation and instrumental tenderness measurements of fresh meat. Chicago, IL: American Meat Sci Association; 1995

34. Simitzis PE, Symeon GK, Charismiadou MA, Bizelis JA, Deligeorgis SG. The effects of dietary oregano oil supplementation on pig meat characteristics. Meat Sci. 2010;79:217-23.

35. Hamill RM, Aslan O, Mullen AM, O'Doherty JV, Mcbryan J. Morris DG, et al. Transcriptome analysis of porcine $\mathrm{M}$ semimembranosus divergent in intramuscular fat as a consequence of dietary protein restriction BMC Genomics. 2013;14:453.

36. Wood JD, Enser M, Fisher AV, Nute GR, Sheard PR, Richardson Rl, et al. Fat deposition, fatty acid composition and meat quality: a review. Meat Sci. 2008;78:343-58 
37. Fiego DPL, Macchioni P, Minelli G, Santoro P. Lipid composition of covering and intramuscular fat in pigs at different slaughter age. Ital J Anim Sci. 2010;9:200-5.

38. Weatherup RN, Beattie VE, Moss BW, Kilpatrick DJ, Walker N. The effect of increasing slaughter weight on the production performance and meat quality of finishing pigs. Anim Sci J. 1999;67:591-600.

39. Jr SR, Mahan DC, Graham PL. Changes in swine body composition from birth to $145 \mathrm{~kg}$. J Anim Sci. 1983;57:43-54.

40. Ranucci D, Beghelli D, Trabalzamarinucci M, Branciari R, Forte C, Olivieri O, et al. Dietary effects of a mix derived from oregano (Origanum Vulgare L.) essential oil and sweet chestnut (Castanea Sativa mill.) wood extract on pig performance, oxidative status and pork quality traits. Meat Sci. 2015;100:319-26.

41. Kelly RF, Bray RW, Phllips PH. The influence of chlortetracycline supplementation of the ration on distribution, quantity and quality of fat deposited in swine. 1. Metabolic effects in relation to carcass composition. J Anim Sci. 1957;16:74-84.

42. Cho I, Yamanishi S, Cox L, Methé BA, Zavadil J, Li K, et al. Antibiotics in early life alter the murine colonic microbiome and adiposity. Nature. 2012;488: 621-6.

43. Terenina MB, Misharina TA, Krikunova NI, Alinkina ES, Fatkulina LD, Vorob'Eva AK. Oregano essential oil as an inhibitor of higher fatty acid oxidation. Appl Biochem Micro. 2011;47:490-4.

44. Gandemer G. Lipids in muscles and adipose tissues, changes during processing and sensory properties of meat products. Meat Sci. 2002;62:309-21.

45. Shu Y, Yu B, He J, Yu J, Zheng P, Yuan Z, et al. Excess of dietary benzoic acid supplementation leads to growth retardation, hematological abnormality and organ injury of piglets. Livest Sci. 2016;190:94-103.

46. Rossi R, Pastorelli G, Cannata S, Tavaniello S, Maiorano G, Corino C. Effect of long term dietary supplementation with plant extract on carcass characteristics meat quality and oxidative stability in pork. Meat Sci. 2013;95:542-8.

47. Asghar A, Gray Jl, Booren AM, Gomaa EA, Abouzied MM, Miller ER, et al. Effects of supranutritional dietary vitamin E levels on subcellular deposition of a-tocopherol in the muscle and on pork quality. J Sci Food Agr. 2010:57:31-41.

48. Zou Y, Hu XM, Zhang T, Wei HK, Zhou YF, Zhou ZX, et al. Effects of dietary oregano essential oil and vitamin E supplementation on meat quality, stress response and intestinal morphology in pigs following transport stress. J Vet Med Sci. 2017:79:328-35.

\section{Submit your next manuscript to BioMed Central and we will help you at every step:}

- We accept pre-submission inquiries

- Our selector tool helps you to find the most relevant journal

- We provide round the clock customer support

- Convenient online submission

- Thorough peer review

- Inclusion in PubMed and all major indexing services

- Maximum visibility for your research

Submit your manuscript at www biomedcentral.com/submit

) Biomed Central 